\title{
Long-term fracture load of all-ceramic crowns: Effects of veneering ceramic thickness, application techniques, and cooling protocol
}

\author{
Júlia-Magalhães-da Costa Lima ${ }^{1}$, João-Paulo-Mendes Tribst ${ }^{2}$, Lilian-Costa Anami ${ }^{3}$, Renata-Marques de Melo ${ }^{2}$, \\ Dayanne-Monielle-Duarte Moura ${ }^{4}$, Rodrigo-Othávio-Assunção e Souza ${ }^{4}$, Marco-Antonio Bottino ${ }^{2}$
}

\author{
${ }^{1}$ DDs, MSc, PhD , University Hospital Lauro Wanderley, Federal University of Paraíba (UFPB), João Pessoa, PB, Brazil \\ ${ }^{2}$ DDs, MSc, PhD, Department of Dental Materials and Prosthodontics, São Paulo State University (Unesp), Institute of Science and \\ Technology, São José dos Campos, São Paulo, Brazil \\ ${ }^{3}$ DDs, MSc, PhD, Departmentof Dentistry, Santo Amaro University, São Paulo, SP, Brazil \\ ${ }^{4}$ DDs, MSc, PhD, Department of Dentistry, Division of Prosthodontics, Federal University of Rio Grande do Norte (UFRN), Natal/ \\ RN, Brazil
}

\section{Correspondence:}

Department of Dental Materials and Prosthodontics

São Paulo State University (Unesp)

Institute of Science and Technology

São José dos Campos / SP, Brazil

Av Engenheiro Francisco José Longo

777, Jardim São Dimas, São José dos Campos

São Paulo, Brazil

joao.tribst@gmail.com

Lima JMC, Tribst JPM, Anami LC, de Melo RM, Moura DMD, Souza ROA, Bottino MA. Long-term fracture load of all-ceramic crowns: Effects of veneering ceramic thickness, application techniques, and cooling protocol. J Clin Exp Dent. 2020;12(11):e1078-85.

Received: 21/05/2020 Accepted: 02/07/2020

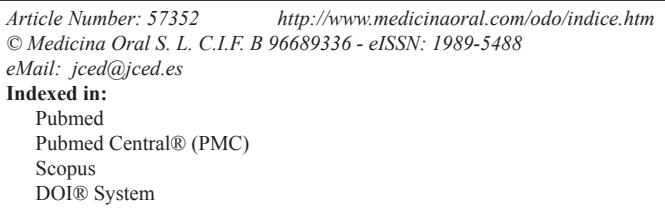

\begin{abstract}
Background: To evaluate, in vitro, the effects of the cooling protocol, application technique, and veneering ceramic thickness on the fracture resistance of ceramic crowns with Y-TZP frameworks.

Material and Methods: 80 frameworks were made from zirconia by the CAD/CAM technique and divided into 8 groups $(\mathrm{n}=10)$ according to the factors: "application technique" (stratified-L and pressed -P), "thickness" (1 mm and $2 \mathrm{~mm}$ ), and "cooling protocol" (slow-S and fast-F) of the feldspathic veneering ceramic. After, all crowns were cemented over G10 preparations with resin cement (Panavia F, Kuraray), mechanically cycled $\left(2 \times 10^{6}\right.$ cycles, 200 $\mathrm{N}, 3 \mathrm{~Hz})$, and subjected to the axial compression resistance test $(0.5 \mathrm{~mm} / \mathrm{min}, 10 \mathrm{kN})$. The data $(\mathrm{N})$ underwent descriptive statistical analysis by 3-way ANOVA and Tukey's test (5\%). Fracture analysis was performed to determine the possible origin of failure.

Results: The factors "cooling protocol" $(P=0.0058)$ and "application" technique $(P=0.0001)$ influenced the fracture

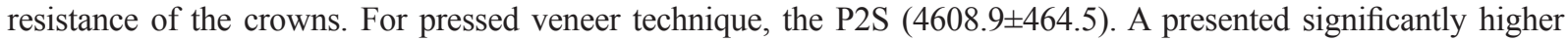
results than that $\mathrm{P} 2 \mathrm{~F}(3621.1 \pm 523.0) \mathrm{BCD}$ (Tukey's test). For the stratified technique, this difference was not observed $(P>0.05)$. The thickness of the veneering ceramic was not significant regardless of the cooling protocol and technique $(P>0.05)$. The predominant failure mode was chipping of the ceramic veneer originating in the subsurface.

Conclusions: The pressed technique, used with a slow-cooling protocol, leads to the best outcome for the veneering of all-ceramic crowns.
\end{abstract}

Key words: Zirconia, ceramics, cooling protocol, thickness, application technique. 


\section{Introduction}

Several studies have been performed to understand the causes of the flaws found in all-ceramic restorations (14). The failure incidence of all-ceramic restorations is related to fractures in the ceramic veneer in $2 \%$ until $25 \%$ of the cases after 3 years of clinical use $(5,6)$. In addition, this type of failure is more predominant than in metal-ceramic restorations, where $19.4 \%$ of failures were observed after 3 years of use $(6,7)$. Several factors may be related to the fracture of all-ceramic restorations, as: material strength, fracture toughness, glass transition temperature, occlusal loads $(8,9)$; anatomical support $(9,10)$; shape and thickness of the framework and the veneering ceramics $(9,11,12)$; ceramic application technique (3); and residual thermal stress (1-8).

Residual thermal stress is present in the ceramic material due to the temperature gradient and the difference between the coefficient of thermal expansion (CTE) between core and ceramic veneer. The residual stress is a relevant factor, widely reported as the major cause of fractures of the veneering ceramics in restorations with zirconia frameworks $(13,14)$. In this context, it has been reported that the manufacture all-ceramic restorations involves a series of sintering thermal cycles and cooling processes, when each new layer of the veneering ceramics material is applied. According to Swain (1), during these firing cycles, the difference in CTEs among the materials (framework/veneering), and the cooling rate after each firing cycle can influence the magnitude of residual stress in the restoration.

When the CTE of the veneering ceramic is higher than that of the framework ceramic, tensile residual stress is generated in the veneering surface, leading to the development of the chipping type of failure. However, if the CTE of the framework is higher than the veneering ceramic, delamination can occur detaching the aesthetic ceramic and the core, due to the tensile residual stresses generated at the interface $(1,4)$. The cooling rate can generate compressive residual stresses in the veneering ceramic surface and tensile residual stresses in the subsurface. There is a directly proportional relationship among cooling rate, thickness, and residual stress development: smaller thickness and slower cooling will lead to lower residual stress in the veneering ceramic (1).

However, it is important to note that the cooling rate and hence the amount of residual stress - depends on the thickness and the geometry of the specimen (15). In this way, a slow-cooling protocol should be established and tested in Y-TZP prostheses covered by ceramic with clinically relevant geometry (16). Another important factor is the manufacturing technique that can be associated with the cohesive failure of the veneering ceramic observed in clinics (16). The layering technique is more sensitive, due to the consecutive applied layers of veneering ceramic, the repetitive sintering firings (17), and the possibility of voids and defects incorporation (18).
Thus, this study aimed to evaluate the effects of thickness, application technique, and the cooling rate of the veneering ceramic on the fracture resistance of all-ceramic crowns with zirconia framework. The hypothesis tested was that the application technique of veneering ceramic, as well as the cooling protocol and the thickness, would influence the fracture resistance of all-ceramic crowns.

\section{Material and Methods}

\section{-Sample preparation}

An anatomical preparation corresponding to a human first molar (6 mm high and ending in a $1.2 \mathrm{~mm}$ chamfer) was designed with three-dimensional (3D) modeling software (Rhinoceros 4.0, Seattle, WA, USA). From the 3D design, 80 preparations were milled in an epoxy-resin-based material reinforced by glass fiber NEMA grade G-10 (International Paper, Hampton, SC, USA), which has mechanical properties similar to those of human dentin (19).

Each G10 preparation had its base embedded in acrylic resin, and one of them was scanned (inEos Blue, Sirona Dental Systems, Bensheim, Germany). A 3D image was generated with the scanner software (Sirona Dental Systems) the finishing line of the preparation was demarcated, the insertion axis was determined and the software virtually designed the crown's framework. From this design, 80 identical zirconia frameworks were obtained from pre-sintered blocks of tetragonal zirconia partially stabilized by yttrium oxide (VITA In-Ceram YZ for inLab, Vita Zahnfabrik) and were milled in a CAD/CAM facility (InLab CEREC MC XL, Sirona Dental Systems). Before sintering, frameworks were cleaned with distilled water in an ultrasound bath for $5 \mathrm{~min}$, then were subjected to a cleaning firing (VITA Vacumat 6000 MP, Vita Zahnfabrik) and were immersed in (Coloring Liquid, LL1, Vita Zahnfabrik) for two minutes, according to one of the protocols recommended by the manufacturer. The sintering process was performed as recommended by the manufacturer (rising time, $1.5 \mathrm{~h}$; end temperature, 1530 ${ }^{\circ} \mathrm{C}$; holding time for end temperature, $2 \mathrm{~h}$; cooling to 400 ${ }^{\circ} \mathrm{C}$ with firing chamber kept closed). After sintering, the zirconia frameworks and G10 preparations were randomly distributed into 8 groups $(\mathrm{n}=10)$ according to the factors: "application technique", "thickness", and "cooling protocol of the veneering ceramic" (Table 1). A calibrated technician applied the veneering ceramic by two different techniques according to the groups (Table 2).

-Heat-pressed Technique

For standardization of the veneer ceramic design, polymer blocks (VITA CAD Waxx, Vita Zahnfabrik) were milled (InLab CEREC MC XL, Sirona Dental Systems) in two different thickness (1 and $2 \mathrm{~mm}$ in the major groove of the occlusal surface). Twenty crowns of each thickness were obtained. 
Table 1: Experimental design according to the different application technique and cooling protocol.

\begin{tabular}{|c|c|c|c|c|c|}
\hline \multirow[b]{2}{*}{$\begin{array}{c}\text { Abutment } \\
\text { (preparation) }\end{array}$} & \multirow{2}{*}{$\begin{array}{c}\text { Framework } \\
\text { ceramic }\end{array}$} & \multicolumn{3}{|c|}{ Veneering ceramic } & \multirow{2}{*}{$\begin{array}{c}\text { Groups } \\
(n=10)\end{array}$} \\
\hline & & $\begin{array}{l}\text { Application } \\
\text { technique }\end{array}$ & $\begin{array}{l}\text { Cooling } \\
\text { protocol }\end{array}$ & Thickness & \\
\hline \multirow{8}{*}{ G10 } & \multirow{8}{*}{$\begin{array}{l}\text { VITA In- } \\
\text { Ceram YZ for } \\
\text { inLab }\end{array}$} & \multirow{4}{*}{$\begin{array}{l}\text { VITA PM9 } \\
\text { (pressed } \\
\text { technique) }\end{array}$} & \multirow{2}{*}{ Fast } & $1 \mathrm{~mm}$ & $\mathrm{P} 1 \mathrm{~F}$ \\
\hline & & & & $2 \mathrm{~mm}$ & P1S \\
\hline & & & \multirow{2}{*}{ Slow } & $1 \mathrm{~mm}$ & $\mathrm{P} 2 \mathrm{~F}$ \\
\hline & & & & $2 \mathrm{~mm}$ & $\mathrm{P} 2 \mathrm{~S}$ \\
\hline & & \multirow{4}{*}{$\begin{array}{c}\text { VITA VM9 } \\
\text { (layering } \\
\text { technique) }\end{array}$} & \multirow{2}{*}{ Fast } & $1 \mathrm{~mm}$ & $\mathrm{~V} 1 \mathrm{~F}$ \\
\hline & & & & $2 \mathrm{~mm}$ & V1S \\
\hline & & & \multirow{2}{*}{ Slow } & $1 \mathrm{~mm}$ & $\mathrm{~V} 2 \mathrm{~F}$ \\
\hline & & & & $2 \mathrm{~mm}$ & V2S \\
\hline
\end{tabular}

Table 2: Sintering cycles for each ceramic material.

\begin{tabular}{|c|c|c|c|c|c|c|c|c|}
\hline Cycles & $\begin{array}{c}\text { Start } \\
\text { temperature } \\
\left({ }^{\circ} \mathrm{C}\right)\end{array}$ & $\begin{array}{l}\text { Pre- } \\
\text { drying } \\
\text { time } \\
(\min )\end{array}$ & $\begin{array}{l}\text { Heating } \\
\text { time } \\
\text { (min) }\end{array}$ & $\begin{array}{c}\text { Temperature } \\
\text { rise rate } \\
\left({ }^{\circ} \mathrm{C} / \mathrm{min}\right)\end{array}$ & $\begin{array}{c}\text { End } \\
\text { temperature } \\
\left({ }^{\circ} \mathrm{C}\right)\end{array}$ & $\begin{array}{c}\text { Holding } \\
\text { time for end } \\
\text { temperature } \\
(\text { min) }\end{array}$ & $\begin{array}{l}\text { Long- } \\
\text { term } \\
\text { cooling } \\
\left({ }^{\circ} \mathrm{C}\right)\end{array}$ & $\begin{array}{l}\text { Vacuum } \\
\text { holding time } \\
\text { (min) }\end{array}$ \\
\hline YZ cleaning & 600 & 3.00 & 3.00 & 33 & 700 & 5.00 & - & 0.00 \\
\hline $\begin{array}{l}\text { VM9 } 1^{\text {st }} \text { firing ("Base } \\
\text { Dentin wash firing") }\end{array}$ & 500 & 6.00 & 7.27 & 55 & 910 & 1.00 & - & 7.27 \\
\hline $\begin{array}{l}\text { VM9 } 2^{\text {nd }} \text { firing (" } 1^{\text {st }} \\
\text { Dentin firing") }\end{array}$ & 500 & 6.00 & 7.16 & 55 & 900 & 1.00 & - & 7.16 \\
\hline \multicolumn{9}{|l|}{ Glaze firing } \\
\hline FAST cooling & 500 & - & 5.00 & 80 & 900 & 1.00 & $800 * *$ & - \\
\hline SLOW cooling & 500 & - & 5.00 & 80 & 900 & 1.00 & $500^{*}$ & - \\
\hline
\end{tabular}

* Furnace $100 \%$ closed during cooling down to this temperature. ${ }^{* *}$ Furnace completely opened.

The polymer crowns were placed over the zirconia framework, and a small amount of sculpture wax was applied to the crown to seal the margin and fix the structures. The sprues were attached to the crowns, and the set was positioned at the center of the sprue-former at a $45^{\circ}$ angle. The coating (Bellavest HS Bego, Bremen, Germany) was mixed and then poured into the silicone mold according to the manufacturer's instructions. After setting, the coating ring was placed in a preheated oven $\left(850{ }^{\circ} \mathrm{C}\right)$ for at least 75 minutes for evaporation of the wax and the polymer.

The ring was immediately transferred to the ceramic oven, and two VITA PM9 tablets (2M1P - Opaque, Vita Zahnfabrik) were pressed. The cycle was performed according to the manufacturer's instructions: firing began at $700{ }^{\circ} \mathrm{C}$ with $0 \mathrm{~min}$ of pre-drying and $6 \mathrm{~min}$ of temperature rise at $50{ }^{\circ} \mathrm{C} \mathrm{per} / \mathrm{min}$ for up to $1000^{\circ} \mathrm{C}$, which was maintained for $20 \mathrm{~min}$, and $3 \mathrm{bar}$ of pressure for $8 \mathrm{~min}$. To remove the crowns, the coating was cut with cutting discs mounted in a hand motor and then sandblasted with $50-\mu \mathrm{m}$ particles of aluminum oxide (Asfer Chemical Ltda, São Caetano do Sul/SP, Brazil).
-Layering Technique

From the two types of crowns obtained by the heat-pressed technique, two molds of silicone were made (Elite HD, Zetaplus System, Zhermack, Badia Polesine, Italy) to standardize all crowns in the present study.

The zirconia frameworks were cleaned in an ultrasound bath with distilled water for $5 \mathrm{~min}$, and the veneering ceramic (VITA VM9, Base Dentine 1M1, Vita Zahnfabrik) was applied by the layering technique with the aid of the molds. The framework surfaces were coated with a mixture of ceramic powder and the modeling liquid (VITA VM9, Modeling Liquid, Vita Zahnfabrik), by means of a brush, and condensed by manual vibration. The excess water was removed with absorbent tissues, and sintering (Table 2) was performed. Two dentin firings were performed to compensate the shrinkage of approximately $12 \%$ that occurred after the firing cycles.

Forty bilayer crowns were made with the same dimensions as the heat-pressed ones: $20,1 \mathrm{~mm}$ thick and 20, $2 \mathrm{~mm}$ thick in the major groove of the occlusal surface. -Cooling protocols

A layer of glaze (VITA Akzent, Vita Zahnfabrik) was 
applied on the crowns, and after the respective firing cycle (Table 2), the crowns were subjected to two different cooling procedures.

During fast cooling, the ceramic furnace (VITA Vacumat 6000 MP Vita Zahnfabrik) was programmed to open immediately after the firing cycle (Table 2), and the crowns were removed from the base of the oven to cool at room temperature $\left(25^{\circ} \mathrm{C}\right)(20)$.

For slow cooling, the same furnace was used (Table 2) and was programmed to remain tightly closed during cooling until the temperature of $500^{\circ} \mathrm{C}$ was reached. Then, the oven was opened, and the crowns were kept in the base of the oven until it reached room temperature. This protocol was based on a previous report (20).

-Cementation procedure

All crowns were cemented to the preparations with a dual-cured resin cement (Panavia F. Kuraray Medical Inc.).

The G10 preparations were etched with 5\% hydrofluoric acid gel for $60 \mathrm{sec}$. The acid was removed with air/water spray for $30 \mathrm{sec}$ and ultrasonically cleaned with distilled water for $5 \mathrm{~min}$. The preparations were dried with oil-free air jets for $30 \mathrm{sec}$, and the silane agent (Clearfil SE Bond Primer and Porcelain Bond Activator, Kuraray Medical Inc.) was applied with a disposable brush. After $5 \mathrm{sec}$, a gentle air jet was applied, and the silane was allowed to evaporate for $60 \mathrm{sec}$. The ED Primer (Kuraray Medical Inc.) was applied to the preparations. After $60 \mathrm{sec}$, it was gently air-dried.

Equal amounts of the resinous cement were mixed for $20 \mathrm{sec}$, and applied to the inner margins of the zirconia framework. Each crown was initially positioned with slight manual pressure over the preparation, and then a $750 \mathrm{~g}$ load was applied at the occlusal surface. The excess cement was removed, and four 40 -second polymerizations were carried out around the set $\left(0^{\circ}, 90^{\circ}, 180^{\circ}\right.$, $270^{\circ}$ ) with a curing light (Curing Light Radii-Cal, SDI, Bayswater, VIC, Australia). The cemented samples were immersed in distilled water at $37^{\circ} \mathrm{C}$ for 24 hours before the mechanical cycling.

-Mechanical cycling

All crowns were subjected to $2 \times 10^{6}$ cycles of $200 \mathrm{~N}$ at $3 \mathrm{~Hz}$ in a mechanical cycling machine (Erios 11000, Erios Technical and Scientific Equipment Ltd., São Paulo, Brazil) immersed in distilled water at $37^{\circ} \mathrm{C}(21)$. The load applicators consisted of solid stainless steel spherical tips (6 $\mathrm{mm}$ in diameter) positioned in the center of the occlusal surface of each crown. An acetate strip was interposed between load applicators and crowns.

After mechanical cycling, each crown was examined in a stereomicroscope (30x, Discovery V20, Zeiss, Jena, Germany) to confirm the absence of chipping or failures due to cycling.

A compressive test was conducted in a universal testing machine (EMIC DL 1000, São José dos Pinhais/PR,
Brazil), at a speed of $0.5 \mathrm{~mm} / \mathrm{min}$ and a $10 \mathrm{kN}$ load cell with a load applicator similar to that used in mechanical cycling. During the test, the samples were kept immersed in distilled water at $37{ }^{\circ} \mathrm{C}$ with the aid of a thermostat, to simulate conditions similar to those of the oral environment. Compression resistance was recorded in $\mathrm{N}$ for each crown at the first sign of failure.

-Failure Analysis

The specimens were examined by stereomicroscopy (70x, Discovery V2, Zeiss) to determine the failure (22). The classification based on the type of fracture: crack - cracking of the veneering ceramic at the interface; chipping - fracture on the surface of the veneering ceramic without exposure of the framework; delamination - fracture of the veneering ceramic with exposure of the framework; and catastrophic - fracture of the veneering ceramic and zirconia framework $(23,24)$. The representative fragments were analyzed by scanning electron microscopy (Inspect S50, FEI Company, Brno, Czech Republic) $(9,16)$.

-Statistical Analysis

The sample's power was calculated through the website www.openepi.com, considering a $95 \%$ confidence interval. After checking the assumptions for normality and homogeneity, the fracture load data were subjected to inferential statistical analysis by parametric variance (3way ANOVA) and multiple comparison by Tukey's test $(\alpha=0.05)$, (Table 3).

\section{Results}

The Power for fracture load data was $96 \%$. The mean and standard deviation (SD) of the maximum force of fracture load $(\mathrm{N})$ and the comparison among experimental groups (Tukey's test 5\%) are presented in Table 4. ANOVA showed that the cooling protocol $(\mathrm{F}=8.08 ; P=$ $0.0058)$ and application technique $(\mathrm{F}=67.1 ; P=0.0001)$ were statistically significant. For pressed veneer technique, the P2S (4608.9 \pm 464.5$)$ A presented significantly higher results than that $\mathrm{P} 2 \mathrm{~F}(3621.1 \pm 523.0) \mathrm{BCD}$. For the stratified technique, no difference among groups was observed $(P>0.05)$.

The failures analysis showed that all crowns presented cone-shaped fracture propagation (cone-crack) of the veneering ceramic from the point of load application, as illustrated in Figure 1. Fractographic analysis showed that the cone-crack began in the subsurface, a few microns below the outer surface where the load was applied (Figs. 2,3). The failure mode classifications are shown in Table 4.

\section{Discussion}

This study was designed to evaluate the effect of thickness, application technique, and the cooling rate of the veneering ceramic on the fracture resistance of all-ceramic crowns with zirconia framework. For this, to simu- 
Table 3: Mean (SD) values of the fracture load (in N) for the experimental groups and Tukey's grouping.

\begin{tabular}{|c|c|c|c|c|}
\hline \multicolumn{3}{|c|}{ Experimental Conditions } & \multirow[b]{2}{*}{ Group } & \multirow[t]{2}{*}{ Mean (SD) } \\
\hline $\begin{array}{l}\text { Application } \\
\text { technique }\end{array}$ & $\begin{array}{l}\text { Cooling } \\
\text { protocol }\end{array}$ & Thickness & & \\
\hline \multirow{4}{*}{ Pressed (PM9) } & \multirow{2}{*}{ Fast } & $1 \mathrm{~mm}$ & P1F & $3941.5(539.0)^{\mathrm{ABC}}$ \\
\hline & & $2 \mathrm{~mm}$ & $\mathrm{P} 2 \mathrm{~F}$ & $3621.1(523.0)^{\mathrm{BCD}}$ \\
\hline & \multirow{2}{*}{ Slow } & $1 \mathrm{~mm}$ & P1S & $4100.3(654.6)^{\mathrm{AB}}$ \\
\hline & & $2 \mathrm{~mm}$ & $\mathrm{P} 2 \mathrm{~S}$ & $4608.9(464.5)^{\mathrm{A}}$ \\
\hline \multirow{4}{*}{$\begin{array}{l}\text { Stratified } \\
\text { (VM9) }\end{array}$} & \multirow{2}{*}{ Fast } & $1 \mathrm{~mm}$ & V1F & $2942.9(416.5)^{\mathrm{D}}$ \\
\hline & & $2 \mathrm{~mm}$ & $\mathrm{~V} 2 \mathrm{~F}$ & $3079.1(500.7)^{\mathrm{D}}$ \\
\hline & \multirow{2}{*}{ Slow } & $1 \mathrm{~mm}$ & V1S & $3028.2(762.4)^{\mathrm{D}}$ \\
\hline & & $2 \mathrm{~mm}$ & V2S & $3232.0(394.94)^{\mathrm{CD}}$ \\
\hline
\end{tabular}

*Values followed by the same letter show no statistical difference $(p>0,05)$.

Table 4: Data distribution according to failures mode classification for each experimental group: number of samples and percentage.

\begin{tabular}{|c|c|c|c|c|}
\hline Groups & Crack & Chipping & Delamination & $\begin{array}{c}\text { Catastrophic } \\
\text { failure }\end{array}$ \\
\hline P1F & $0(0 \%)$ & $4(40 \%)$ & $6(60 \%)$ & $0(0 \%)$ \\
\hline P2F & $0(0 \%)$ & $10(100 \%)$ & $0(0 \%)$ & $0(0 \%)$ \\
\hline P1S & $0(0 \%)$ & $8(80 \%)$ & $1(10 \%)$ & $1(10 \%)$ \\
\hline P2S & $0(0 \%)$ & $10(100 \%)$ & $0(0 \%)$ & $0(0 \%)$ \\
\hline V1F & $0(0 \%)$ & $8(80 \%)$ & $0(0 \%)$ & $2(30 \%)$ \\
\hline V2F & $0(0 \%)$ & $9(90 \%)$ & $0(0 \%)$ & $1(10 \%)$ \\
\hline V1S & $0(0 \%)$ & $8(80 \%)$ & $0(0 \%)$ & $2(20 \%)$ \\
\hline V2S & $0(0 \%)$ & $6(60 \%)$ & $0(0 \%)$ & $4(40 \%)$ \\
\hline Total & $0(0 \%)$ & $63(78.75 \%)$ & $7(8.75 \%)$ & $10(125 \%)$ \\
\hline
\end{tabular}

late the influence of aging (25) on the fracture load of all-ceramic crowns, the mechanical cycling was performed with 2 million cycles and a $200 \mathrm{~N}$ load, simulating a longer period (ca. 8.5 years) of clinical use $(26,27)$. The applied load simulate the chewing in the posterior area (246.9 to $2091.9 \mathrm{~N}$ with an average of $(776.7 \mathrm{~N})(28)$. In Roark's Formulas (29), the solution to measure the contact pressure of a 'sphere on sphere' case was used to calculate the stress between the cusp and the sphere in the present study. The highest load-to-fracture $(\mathrm{N})$ of the present study and a cusp curvature radius of $\sim 5,5.10-3 \mathrm{~m}$ to calculate the maximum contact pressure on the cusp during fracture, which was $\sim 17.103 \mathrm{MPa}$. The maximum chewing force mentioned previously corresponds to $\sim 13.103 \mathrm{MPa}$. This means that, in a real crown, the material would hardly break under the forces applied in the present study, although fatigue in the mouth tends to diminish the fracture load of materials.

Nevertheless, fracture can occur when an excessive load is applied to the crown, due to parafunction such as clen- ching and bruxism, in which the forces applied are of great magnitude and short duration (24,30-32).

The results of the present study were higher than those reported previously $(23,33-35)$, especially for heat-pressed crowns cooled slowly. The reported diversity of values for fracture load may be due to the different designs of the specimens, thicknesses, resinous cement, and different materials used to simulate the tooth preparation (36).

Similar to other studies $(4,8,34,36)$, this study considered crowns with clinically relevant anatomy, varying the thickness of the veneering ceramic and keeping their shapes similar, despite the application technique or the thickness of the veneering ceramic. Crowns with anatomical frameworks have higher fracture toughness and lower incidence of fractures in the veneering ceramic $(5,36)$, often resulting in failures of easy repair and without functional and esthetic impairment (35). Comparing fracture strength of non-anatomical and anatomical crowns, a previous study (34) found that the negative 

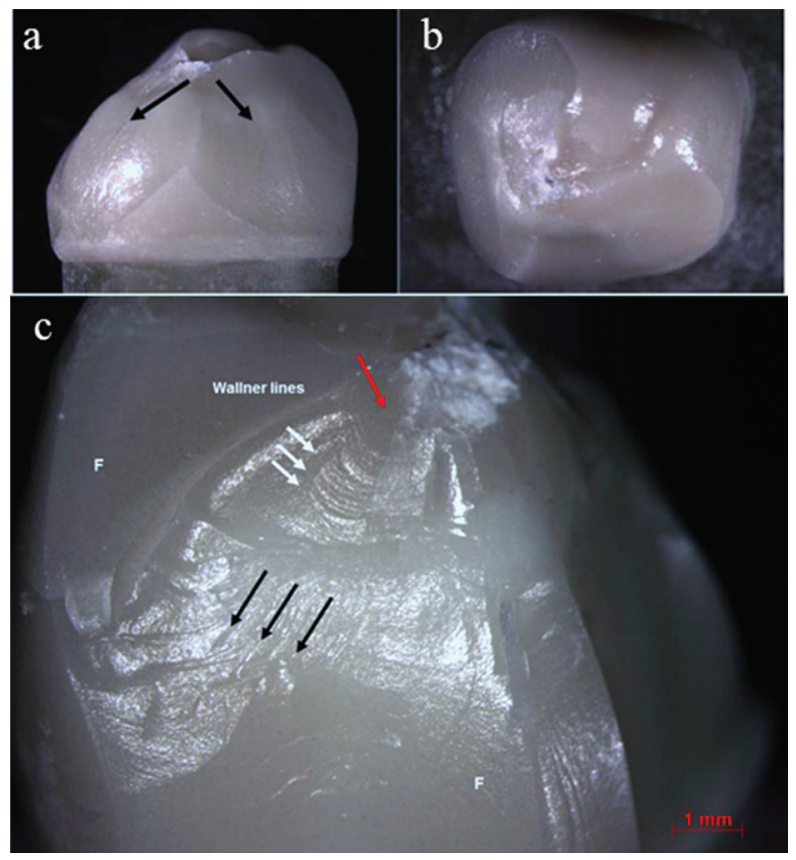

Fig. 1: a) Representative stereomicroscope image $(7,5 \mathrm{x})$ of a coneshaped fracture propagation (cone crack) of the veneering ceramic, b) chipping without framework failure of a crown from group V1F, c) Stereomicroscope image (10x) of a P2S crown failed by chipping. The black arrows indicate the direction of the failure in the feldspathic ceramic; the red arrow indicate the area of the probable failure's origin and the white arrow indicate the wallner lines. F: feldspathic veneering ceramic. effects of high brittleness of the veneering ceramics were reduced in anatomical crowns.

Furthermore, the fractures of the veneering ceramic were greater in extent for non-anatomical crowns (1). It can occurs because the adequate support for the veneering ceramic creates a favorable conditions to reduce the stress, increasing the fracture load. In addition, the greater thicknesses of the zirconia in non-anatomical crowns generate more residual tensile stress, resulting in higher incidence of fractures (34).

According to the present study results, the hypothesis that the application technique of veneering ceramic, as well as the cooling protocol and the thickness, would influence the fracture resistance of all-ceramic crowns, was partially accepted. Regarding the thickness, it has been reported that thicker veneering ceramic are related to reduced restoration strength, due to the ceramic is susceptibility to subsurface residual stresses $(1,2,33)$. However, the restoration thickness depends on the antagonist tooth, occlusal space, preparation and anatomy (35). Some studies claim that greater thicknesses of veneering ceramic are related to lower load to fracture $(1,2,33)$. Smaller ceramic thicknesses led to reduced stress generated due to shrinkage during the cooling process (11). It would thus be expected that resistance would be better with smaller thicknesses. However, in this study, thickness did not influence fracture resistance.
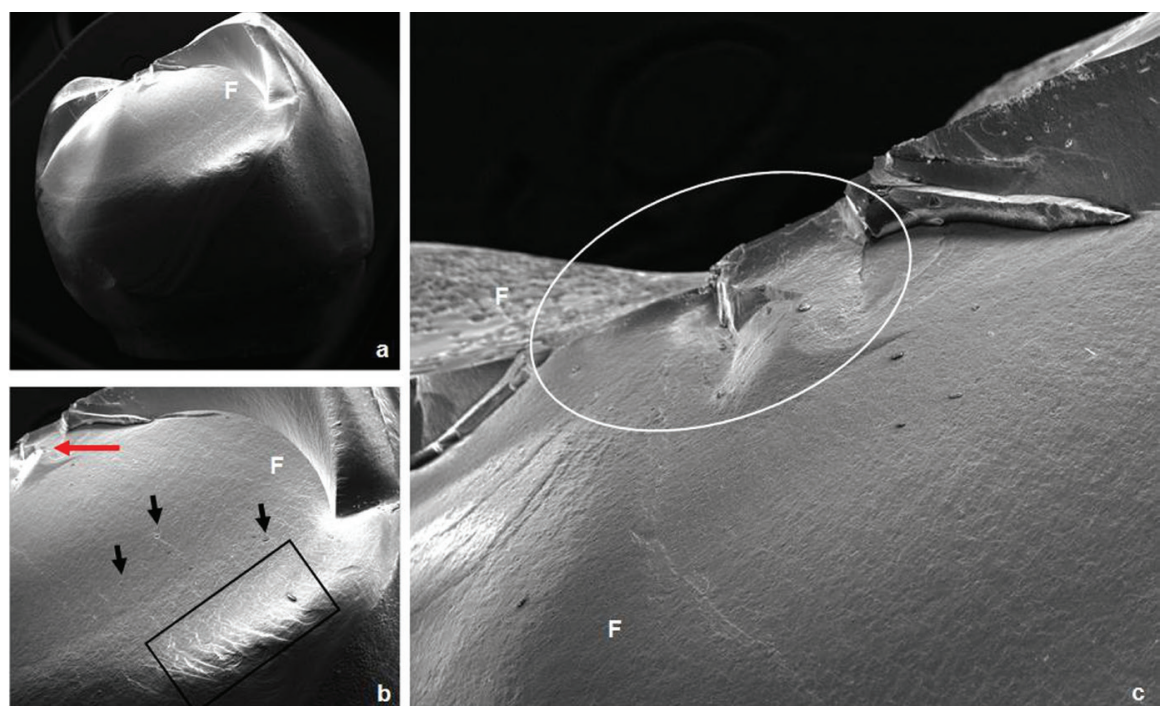

Fig. 2: SEM photomicrographs of a crown from $\mathrm{P} 2 \mathrm{~S}$ group failed by chipping. a) Overview of the fracture (24x). b) The red arrow indicates the area of load application; the presence of wake hackles (black arrows) indicates the direction of fracture propagation; it is possible to observe the compression curl (black rectangle) (70x). c) Closer image of the area under the load application (white ellipse); it can be seen that the pressed technique shows fewer porosities (90x). F: feldspathic veneering ceramic. 

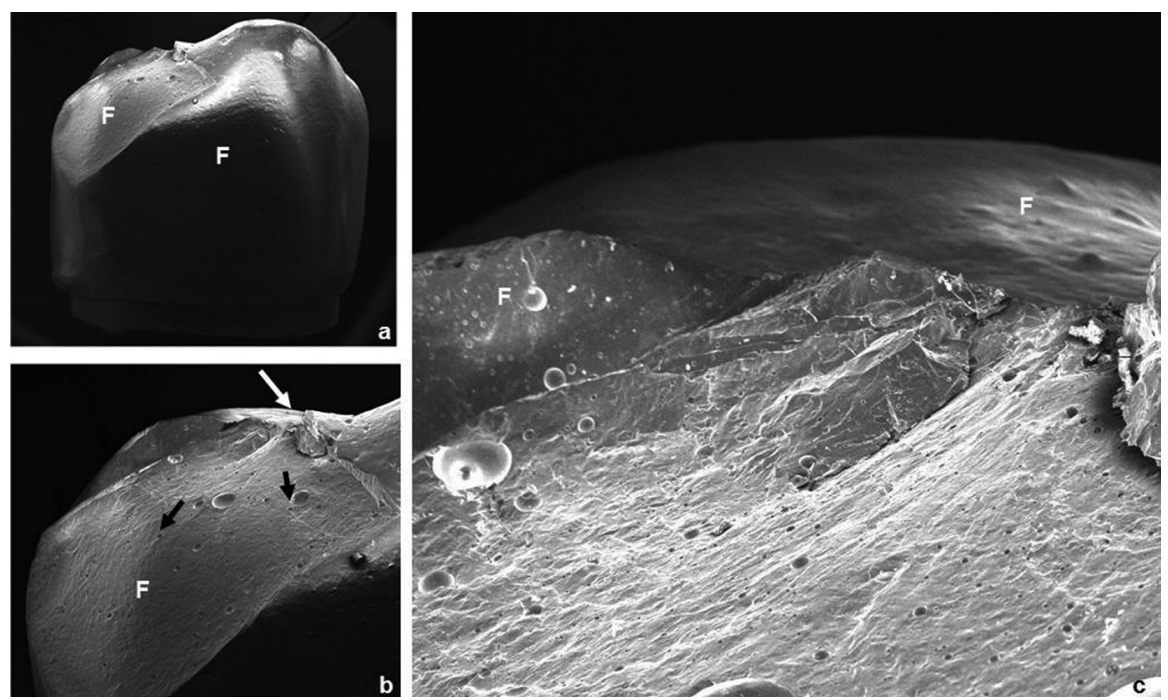
Fig. 3: SEM photomicrographs of a crown from V2F group failed by chipping. a) Overview of the
fracture $(22 \mathrm{x})$. b) The area of load application is indicated by the white arrow; the presence of wake hackles (black arrows) indicates the direction of failure propagation (60x). c) Closer view of the area under the load application; it can be observed the presence of many bubbles resulted from the stratified technique (150x). F: feldspathic veneering ceramic.

The veneering ceramic application technique is a factor that can influence the mechanical properties of the restorations when the inherent characteristics of the materials are considered $(33,35)$. In the present study, the mechanical properties of the two veneering ceramics used are similar (PM9, $100 \mathrm{MPa}, 9.0-9.5 \times 10^{-6} \mathrm{~K}^{-1}$; VM9, $\left.100 \mathrm{MPa}, 8.0-9.2 \times 10^{-6} \mathrm{~K}^{-1}\right)(35)$ however statistically significant differences was found for the application technique. Therefore, it is believed that the technique is a significant factor regardless the restorative material properties. The lower fracture resistance values of the layering restoration can be explained by the increased sintering cycles in which the crown is subjected, resulting in a higher tensile residual stress, especially in areas without support (35), despite the fact that this is a more sensitive and critical technique $(37,38)$. The best results found for the heat-pressed crowns can be explained by the higher density and reduced incorporation of failures (porosities), since this technique is more controlled than the layering technique (18). The heat-pressed technique showed the best results for both cooling protocols, especially for slow cooling.

A previous study that used anatomical crowns to compare the two application techniques found lower fracture load for heat-pressed technique. The authors believe that the lack of experience with the heat-pressed technique may have influenced the results (35). Moreover, these authors did not consider the influence of slow cooling on fracture load, which proved to be a significant factor in the present study.

Regarding the cooling protocol, the results of the present study showed that when the slow-cooling and the heat-pressed techniques were adopted, there was a signi- ficant increase in fracture load. During the manufacture of the crowns, whether fully ceramic or metal-ceramic, several ceramic layers are applied, to obtain the required anatomy and achieve the desired anatomy. Each layer is subjected to sintering cycles with temperatures significantly above the glass transition temperature of the veneering ceramic (usually around $600^{\circ} \mathrm{C}$ ) $(1,3)$. A slower cooling temperature is important in the final firing cycle, once the stress introduced in the first firing cycle is relaxed in the next firing cycle (1).

The predominant failure type was chipping of the veneering ceramic, and there were a few samples with the infrastructure impairment. These findings are consistent with those of clinical report that found a higher number of cohesive failures in which a quantity of veneering ceramic remained on the framework (34). An in vitro study (35) also observed cohesive failure as the predominant failure mode. In the present study, determination of the exact origin of failure was hampered due to the high load required for fracture of these crowns, resulting in areas of destruction under the region of load application. Some findings, such as wake hackles and Wallner lines, indicated the direction of crack propagation.

In conclusion, the fracture resistance of zirconia framework crowns is not influenced by veneering ceramic thickness. The pressed technique, used with a slow-cooling protocol, leads to the best outcome for the veneering of all-ceramic crowns.

\section{References}

1. Swain MV. Unstable cracking (chipping) of veneering porcelain on all-ceramic dental crowns and fixed partial dentures. Acta Biomater. 2009;5:1668-1677. 
2. Soares LM, Soares C, Miranda ME, Basting RT. Influence of Core-Veneer Thickness Ratio on the Fracture Load and Failure Mode of Zirconia Crowns. J Prosthodont. 2019;28:209-215.

3. Dhital S, Rodrigues C, Zhang Y, Kim J. Viscoelastic finite element evaluation of transient and residual stresses in dental crowns: Design parametric study. J Mech Behav Biomed Mater. 2020;103:103545.

4. Swain MV, Mercurio V, Tibballs JE, Tholey M. Thermal induced deflection of a porcelain-zirconia bilayer: Influence of cooling rate. Dent Mater. 2019;35:574-584.

5. Örtorp A, Lindh Kihl M, Carlsson GE. A 3-year retrospective and clinical follow-up study of zirconia single crowns performed in a private practice. J Dent. 2009;37:731-736.

6. Sailer I, Gottnerb J, Kanelb S, Hammerle CH. Randomized controlled clinical trial of zirconia-ceramic and metal-ceramic posterior fixed dental prostheses: a 3-year follow-up. Int J Prosthodont. 2009;22:553560 .

7. Scurria MS, Bader JD, Shugars DA. Meta-analysis of fixed partial denture survival: Prostheses and abutments. J Prosthet Dent 1998;79:459-464.

8. Tribst JPM, Dal Piva AMO, Penteado MM, Borges ALS, Bottino MA. Influence of ceramic material, thickness of restoration and cement layer on stress distribution of occlusal veneers. Braz Oral Res. 2018;32:e118.

9. Lorenzoni FC, Martins LM, Silva NR, Coelho PG, Guess PC, Bonfante EA, Thompson VP, Bonfante G. Fatigue life and failure modes of crowns systems with a modified framework design. J Dent. 2010;38:626-634.

10. Tholey MJ, Swain MV, Thiel N. Thermal gradients and residual stresses in veneered Y-TZP frameworks. Dent Mater. 2011;27:11021110.

11. Mainjot AK, Schajer GS, Vanheusden AJ, Sadoun MJ. Influence of zirconia framework thickness on residual stress profile in veneering ceramic: measurement by hole-drilling. Dent Mater. 2012;28:378-384. 12. Mainjot AK, Schajer GS, Vanheusden AJ, Sadoun MJ. Influence of veneer thickness on residual stress profile in veneering ceramic: measurement by hole-drilling. Dent Mater. 2012;28:160-167.

13. Tanaka CB, Ballester RY, De Souza GM, Zhang Y, Meira JBC. Influence of residual thermal stresses on the edge chipping resistance of PFM and veneered zirconia structures: Experimental and FEA study. Dent Mater. 2019;35(2):344-355.

14. Quinn JB, Quinn G, Sundar V. Fracture Toughness of Veneering Ceramics for Fused to Metal (PFM) and Zirconia Dental Restorative Materials. J Res Natl Inst Stand Technol. 2010;115:343-352.

15. Zhang Y, Allahkarami M, Hanan JC. Measuring residual stress in ceramic zirconia-porcelain dental crowns by nanoindentation. J Mech Behav Biomed Mater. 2012;6:120-127.

16. Bonfante EA, Coelho PG, Guess PC, Thompson VP, Silva NR. Fatigue and damage accumulation of veneer porcelain pressed on Y-TZP. J Dent. 2010;38:318-324.

17. Holand W, Schweiger M, Frank M, Rheinberger V. A comparison of the microstructure and properties of the IPS Empress 2 and the IPS Empress glass-ceramics. J Biomed Mater Res (Appl Biomater). 2000;53:297-303.

18. Tsalouchou E, Cattell MJ, Knowles JC, Pittayachawan P, McDonald A. Fatigue and fracture properties of yttria partially stabilized zirconia crown systems. Dent Mater. 2008;24:308-318.

19. Dal Piva AO, Tribst JP, Borges AL, de Melo RM, Bottino MA. Influence of substrate design for in vitro mechanical testing. J Clin Exp Dent. 2019;11:e119-e125.

20. Tan JP, Sederstrom D, Polansky JR, McLaren EA, White SN. The use of slow heating and slow cooling regimens to strengthen porcelain fused to zirconia. J Prosthet Dent. 2012;107:163-169.

21. Lima JM, Souza AC, Anami LC, Bottino MA, Melo RM, Souza RO. Effects of thickness, processing technique, and cooling rate protocol on the flexural strength of a bilayer ceramic system. Dent Mater. 2013;29:1063-1072.

22. Burke FJ. Fracture resistance of teeth restored with dentin-bonded crowns: the effect of increased tooth preparation. Quintessence Int. 1996;27:115-121.
23. Zahran M, El-Mowafy O, Tam L, Watson PA, Finer Y. Fracture strength and fatigue resistance of all-ceramic molar crowns manufactured with CAD/CAM technology. J Prosthodont. 2008;17:370-377. 24. Aboushelib MN, Feilzer AJ, Kleverlaan CJ. Bridging the gap between clinical failure and laboratory fracture strength tests using a fractographic approach. Dent Mater. 2009;25:383-391

25. Riedel C, Wendler M, Belli R, Petschelt A, Lohbauer U. In vitro lifetime of zirconium dioxide-based crowns veneered using Rapid Layer Technology. Eur J Oral Sci. 2019;127:179-186.

26. Rosentritt M, Behr M, Gebhard R, Handel G. Influence of stress simulation parameters on the fracture strength of all-ceramic fixed-partial dentures. Dent Mater. 2006;22:176-182

27. Att W, Grigoriadou M, Strub JR. ZrO2 three-unit fixed partial dentures: comparison of failure load before and after exposure to a mastication simulator. J Oral Rehabil. 2007;34:282-290.

28. Hattori Y, Satoh C, Kunieda T, Endoh R, Hisamatsu H, Watanabe $\mathrm{M}$. Bite forces and their resultants during forceful intercuspal clenching in humans. J Biomech. 2009;42:1533-1538.

29. Young WC, Budynas RG, Sadegh AM. Roark' Formulas for stress and strain. Eighth edition. New York: McGraw-Hill; 2011:174.

30. Lan TH, Pan CY, Liu PH, Chou MMC. Fracture Resistance of Monolithic Zirconia Crowns in Implant Prostheses in Patients with Bruxism. Materials (Basel). 2019;12:1623.

31. Ferrario VF, Sforza C, Zanotti G, Tartaglia GM. Maximal bite forces in healthy young adults as predicted by surface electromyography. J Dent. 2004;32:451-457.

32. Koenig V, Vanheusden AJ, Le Goff SO, Mainjot AK. Clinical risk factors related to failures with zirconia-based restorations: An up to 9-year retrospective study. J Dent. 2013;41:1164-74.

33. Rosentritt M, Behr M, Thaller C, Rudolph H, Feilzer A. Fracture performance of computer-aided manufactured zirconia and alloy crowns. Quintessence Int. 2009;40:655-662.

34. Larsson C, El Madhoun S, Wennerberg A, Vult von Steyern P. Fracture strength of yttria-stabilized tetragonal zirconia polycrystals crowns with different design: an in vitro study. Clin Oral Implants Res. 2012;23:820-826.

35. Guess PC, Bonfante EA, Silva NR, Coelho PG, Thompson VP. Effect of core design and veneering technique on damage and reliability of Y-TZP-supported crowns. Dent Mater. 2013;29:307-316.

36. Sundh A, Sjogren G. A comparison of fracture strength of yttrium-oxide-partially-stabilized zirconia ceramic crowns with varying core thickness, shapes and veneer ceramics. J Oral Rehabil. 2004;31:682-688.

37. Tezulas E, Yildiz C, Kucuk C, Kahramanoglu E. Current status of zirconia-based all-ceramic restorations fabricated by the digital veneering technique: a comprehensive review. Int J Comput Dent. 2019;22:217-230.

38. Guess PC, Zavanelli RA, Silva NR, Bonfante EA, Coelho PG, Thompson VP. Monolithic CAD/CAM lithium disilicate versus veneered Y-TZP crowns: comparison of failure modes and reliability after fatigue. Int J Prosthodont. 2010;23:434-442.

\section{Acknowledgments}

Grants \# 2011/13085-9, \#2017/23059-1 and \#2017/09104-4, São Paulo Research Foundation (FAPESP).

\section{Conflict of interest}

Non declared. 